\title{
Continuous EEG for Diagnosis of Electrographic Seizures in the Pediatric Cardiac Critical Care Unit: Using a Precious Resource Wisely
}

\author{
Saptharishi Lalgudi Ganesan ${ }^{1,2,3^{*}}$
}

@ 2021 Springer Science+Business Media, LLC, part of Springer Nature and Neurocritical Care Society

Our ability to treat congenital heart defects (CHD) has improved significantly over the last few decades. CHDs, such as transposition of great arteries, that were once considered uniformly fatal now have an operative mortality of approximately 2\% [1]. As mortality in children with CHD declines because of advancements in surgical, anesthetic, and perioperative care, our focus has rightly shifted to optimizing long-term neurological outcomes in these children.

We know that up to one half of infants with CHD are at risk for significant neurodevelopmental impairments [2] and that, in these infants, brain injury is occurring during the prenatal, postnatal preoperative, intraoperative, and immediate postoperative periods [3]. This brain injury usually manifests acutely with seizures, altered level of consciousness, or focal neurological deficits. Seizures can also make the brain injury worse by inducing a metabolic crisis and causing excitotoxic neuronal injury [4]. Electrographic seizures (ES) occurring during the postoperative phase have been reported in $4-18 \%$ of these infants [5-7] and have been associated with brain injury as well as adverse outcomes [4, 8-13]. Children with perioperative ES during infancy show evidence of lower mean intelligence quotient scores at 4 years of age [10], social and attention problems at 8 years of age [11], and overall

\footnotetext{
*Correspondence: rishi.ganesan@lhsc.on.ca

${ }^{1}$ Children's Hospital of Western Ontario, London Health Sciences Center, London, ON, Canada
}

Full list of author information is available at the end of the article

This article is related to the Original article available at https://doi.org/10. 1007/s12028-021-01313-1.

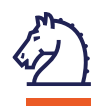

\section{Springer}

increased neurodevelopmental risk at 16 years of age [13].

Despite the understanding that postoperative ES are associated with short-term and long-term adverse outcomes, there are two major challenges to mitigating the risk of ES-associated brain injury in these children. Firstly, because most of the ES are subclinical, continuous electroencephalographic (EEG) monitoring is required for diagnosis, but EEG is a very resource-intensive monitoring modality that requires expensive equipment and around-the-clock availability of neurophysiologists [14-17]. Secondly, there is no evidence that aggressive treatment of ES in these children is associated with improvement in long-term outcomes [4]. ES could also be just an epiphenomenon, a symptom of brain injury sustained in the perioperative time window.

This important study by Levy RJ and colleagues [18] attempts to tackle the first challenge by enabling precise identification of the subgroup of children who are critically ill with CHD at risk for ES in the postoperative period, i.e., a subgroup that could potentially benefit from continuous EEG monitoring. A strength of the study is that every infant less than 3 months of age undergoing cardiopulmonary bypass $(\mathrm{CPB})$ during the study period was enrolled and underwent EEG monitoring for $48 \mathrm{~h}$. This study is relevant and timely for two important reasons: Firstly, most of the studies on ES in children with CHD were conducted in an era wherein deep hypothermic cardiac arrest (DHCA) was the predominant intraoperative strategy used to minimize cerebral metabolism and ensure a clean surgical field during CPB [19]. However, with increasing recognition of the advantages of 
alternate strategies, DHCA is less commonly used. With decreasing use of DHCA, ES have become less common, and the DHCA duration thresholds previously used for risk stratification have become less useful at the bedside $[20,21]$. With this and many other changes to perioperative care of these infants, it is timely that this study has reevaluated ES incidence and its risk profile. Secondly, because the incidence of postoperative seizures continues to decrease, it is becoming increasingly difficult to justify screening all infants post $\mathrm{CPB}$ using continuous EEG monitoring. The yield and cost-effectiveness of this strategy will be unacceptable for most institutions. Therefore, we need to direct our attention to identifying those at risk so that the limited and expensive EEG monitoring resources can be offered to only this subgroup. If validated in future prospective studies, this model will allow more appropriate use of scarce EEG resources and more personalized medicine.

The results of this study must, however, be interpreted with the following considerations: Firstly, because of the retrospective nature of the study, the investigators did not have sufficient data to calculate validated severity of critical illness scores, such as Pediatric Risk of Mortality (PRISM III) or Pediatric Index of Mortality (PIM-2), and perioperative risk stratification scores used in the pediatric cardiac critical care unit, such as Risk Adjustment in Congenital Heart Surgery (RACHS-1) or The Society of Thoracic Surgeons-European Association for CardioThoracic Surgery (STAT) scores. Many factors that have surfaced in the final model represent 'quantity of therapy' and are surrogates for severity of critical illness or perioperative cardiac dysfunction. The authors rightly conclude that the sicker the infant is during the perioperative period, the higher the likelihood that the infant will have seizures. It would be interesting to evaluate if a combination of existing severity of critical illness and perioperative risk stratification scores predicts risk for seizures comparably well in this population. Secondly, with a sample size of 112 and the outcome of interest (seizures) occurring in 12 infants, inclusion of 88 variables in the model with the final model having 14 variables introduces a significant risk of overfitting. The authors have attempted to overcome this by employing a random forest (RF) modeling with many trees $(n=5000)$. However, RF modeling suffers from poor interpretability and fails to determine the significance of each variable in the final model. RF algorithms may also change considerably with a small change in the data. Also, no statistical modeling technique, however robust, can fully compensate for limited sample size. Thirdly, this model needs prospective external validation. Predictive and prognostic models are abundant in the medical literature, but few are externally validated, implemented, or used in clinical practice [22,
23]. Worse still, few models are evaluated for their impact on health outcomes. Currently, this is a huge gap in the prognostic and predictive research realm.

In summary, I congratulate the authors for attempting to make EEG monitoring in this vulnerable population more high-yield and cost-effective. Concerns regarding adverse impacts of postoperative seizures in infant who are critically ill with CHD will remain in the realms of research unless we work together to (1) precisely identify the subgroups at risk, (2) engage with stakeholders to understand barriers to EEG monitoring, (3) educate intensivists regarding potential adverse impact of seizures, and (4) make it cost-effective for institutions to implement a program that enables timely diagnosis and treatment of seizures.

\section{Author details \\ ${ }^{1}$ Children's Hospital of Western Ontario, London Health Sciences Center, London, ON, Canada. ${ }^{2}$ Department of Pediatrics, Schulich School of Medicine and Dentistry, Western University, London, ON, Canada. ${ }^{3}$ Brain and Mind Institute, Western University, London, ON, Canada.}

\section{Source of support}

None.

Conflict of interest

The author has nothing to disclose.

\section{Publisher's Note}

Springer Nature remains neutral with regard to jurisdictional claims in published maps and institutional affiliations.

Received: 28 June 2021 Accepted: 1 July 2021

Published online: 30 July 2021

\section{References}

1. Congenital Heart Surgery Database. The Society of Thoracic Surgeons, Chicago. 2021 https://www.sts.org/registries-research-center/sts-natio nal-database/congenital-heart-surgery-database. Accessed 29 May 2021.

2. Marino BS, Lipkin PH, Newburger JW, Peacock G, Gerdes M, Gaynor JW, et al. Neurodevelopmental outcomes in children with congenital heart disease: evaluation and management: a scientific statement from the American Heart Association. Circulation. 2012;126(9):1143-72.

3. Mebius MJ, Kooi EMW, Bilardo CM, Bos AF. Brain injury and neurodevelopmental outcome in congenital heart disease: a systematic review. Pediatrics. 2017;140(1):e20164055.

4. Lalgudi Ganesan S, Hahn CD. Electrographic seizure burden and outcomes following pediatric status epilepticus. Epilepsy Behav. 2019;101(Pt B):106409.

5. Clancy RR, McGaurn SA, Wernovsky G, Gaynor JW, Spray TL, Norwood WI, et al. Risk of seizures in survivors of newborn heart surgery using deep hypothermic circulatory arrest. Pediatrics. 2003;111(3):592-601.

6. Helmers SL, Wypij D, Constantinou JE, Newburger JW, Hickey PR, Carrazana $E J$, et al. Perioperative electroencephalographic seizures in infants undergoing repair of complex congenital cardiac defects. Electroencephalogr Clin Neurophysiol. 1997;102(1):27-36.

7. Ehyai A, Fenichel GM, Bender HW Jr. Incidence and prognosis of seizures in infants after cardiac surgery with profound hypothermia and circulatory arrest. JAMA. 1984;252(22):3165-7. 
8. Abend NS, Wagenman KL, Blake TP, Schultheis MT, Radcliffe J, Berg RA, et al. Electrographic status epilepticus and neurobehavioral outcomes in critically ill children. Epilepsy Behav. 2015;49:238-44.

9. Rappaport LA, Wypij D, Bellinger DC, Helmers SL, Holmes GL, Barnes $\mathrm{PD}$, et al. Relation of seizures after cardiac surgery in early infancy to neurodevelopmental outcome. Boston Circ Arrest Study Group Circul. 1998;97(8):773-9.

10. Bellinger DC, Wypij D, Kuban KC, Rappaport LA, Hickey PR, Wernovsky $\mathrm{G}$, et al. Developmental and neurological status of children at 4 years of age after heart surgery with hypothermic circulatory arrest or low-flow cardiopulmonary bypass. Circulation. 1999;100(5):526-32

11. Bellinger DC, Newburger JW, Wypij D, Kuban KCK, duPlesssis AJ, Rappaport LA. Behaviour at eight years in children with surgically corrected transposition: the Boston Circulatory Arrest Trial. Cardiol Young. 2009;19(1):86-97.

12. Bellinger D, Watson C, Rivkin M, Robertson R, Roberts A, Stopp C, et al. Neuropsychological status and structural brain imaging in adolescents with single ventricle who underwent the fontan procedure. J Am Heart Assoc. 2015;4(12):e002302.

13. Bellinger D, Wypij D, Rivkin M, DeMaso D, Robertson R, Dunbar-Masterson C, et al. Adolescents with d-transposition of the great arteries corrected with the arterial switch procedure: neuropsychological assessment and structural brain imaging. Circulation. 2011;124(12):1361-9.

14. Lalgudi Ganesan S, Stewart CP, Atenafu EG, Sharma R, Guerguerian A-M, Hutchison JS, et al. Seizure identification by critical care providers using quantitative electroencephalography. Crit Care Med. 2018;46(12):e1105-11.
15. Abend NS, Topjian AA, Williams S. Could EEG monitoring in critically ill children be a cost-effective neuroprotective strategy? J Clin Neurophysiol. 2015;32(6):486-94.

16. Abend NS, Topjian AA, Williams S. How much does it cost to identify a critically ill child experiencing electrographic seizures? J Clinical Neurophysiol. 2015;32(3):257-64.

17. Abend NS, Gutierrez-Colina AM, Topjian AA, Zhao H, Guo R, Donnelly M, et al. Nonconvulsive seizures are common in critically ill children. Neurology. 2011;76(12):1071-7.

18. Levy RJ, Mayne EW, Sandoval Karamian AG, Iqbal M, Purington N, Ryan $\mathrm{KR}$, et al. Evaluation of seizure risk in infants after cardiopulmonary bypass in the absence of deep hypothermic cardiac arrest. Neurocrit Care. 2021. https://doi.org/10.1007/s12028-021-01313-1.

19. Tian DH, Wan B, Bannon PG, Misfeld M, LeMaire SA, Kazui T, et al. A meta-analysis of deep hypothermic circulatory arrest versus moderate hypothermic circulatory arrest with selective antegrade cerebral perfusion. Ann Cardiothorac Surg. 2013;2(2):148-58.

20. Xie L, Xu Y, Huang G, Ye M, Hu X, Shu S, et al. MHCA with SACP versus DHCA in pediatric aortic arch surgery: a comparative study. Sci Rep. 2020;10(1):4439.

21. Mahle W. Boston circulatory arrest study at 16 years: handing over the keys. Circulation. 2011;124(12):1319-20.

22. Wyatt JC, Altman DG. Commentary: prognostic models: clinically useful or quickly forgotten? BMJ. 1995;311:1539.

23. Perel P, Edwards P, Wentz R, Roberts I. Systematic review of prognostic models in traumatic brain injury. BMC Med Inform Decis Mak. 2006:6:38. 